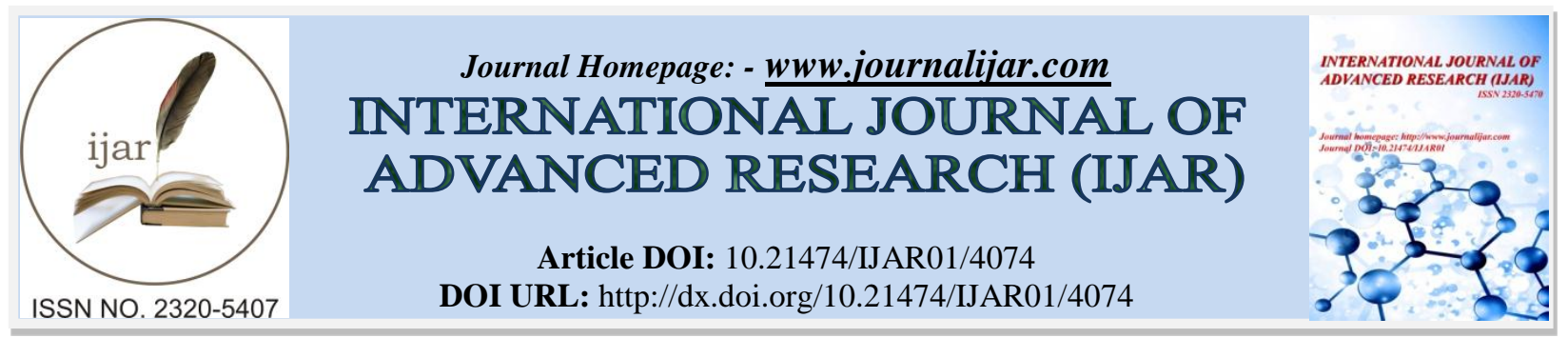

RESEARCH ARTICLE

\title{
AN ASSESSMENT OF THE PRACTICE OF COMPUTERISED DIGITAL RADIOGRAPHY AT THE BAFOUSSAM REGIONAL HOSPITAL
}

\section{Macclevis Daki Awo ${ }^{1}$, Samuel Nambile Cumber ${ }^{2}$, Keneth Nkeh Nchanji ${ }^{1}$ and Godlove Akumbom ${ }^{1}$}

1. St Louis University Institute of Health and Biomedical Sciences Bamenda, Cameroon.

2. Discipline of Public Health Medicine, Department of Nursing \& Public Health, College of Health Sciences, University of KwaZulu-Natal Durban, South Africa.

\section{Manuscript Info}

Manuscript History

Received: 01 March 2017

Final Accepted: 05 April 2017

Published: May 2017

Key words:-

Computerized; Digital; Radiography;

Assessment; Cameroon

\begin{abstract}
Medical diagnostic X-rays are the largest source of ionizing radiation received by members of the general public. The main objective of this study was to evaluate the practice of computerized Digital Radiography(DR) at the Bafoussam Regional Hospital (CRIMO). During a four-week period, radiographers were assessed through the use of structured questionnaires and radiographs examined using an observation form. At the end of the study, the collected data were compiled and analysised, the results showed the highest image retakes with reasons of which $37 \%$ was due to poor parameters, $31 \%$ due to poor positioning, $17 \%$ due to patient motion and $15 \%$ due to cassette artifacts, and most of the participants $(80 \%)$ were for the fact that Digital Radiography has improved performance and work flow while $20 \%$ were against the fact. Based on the findings of this study and discussion, it was concluded that the practice of Digital Radiography at CRIMO is poor and something has to be done to improve on it.
\end{abstract}

Copy Right, IJAR, 2017,. All rights reserved.

\section{Background:-}

The foundation of Digital Radiography lies in the discovery of X-rays by Professor Wilhelm Conrad Roentgen of the University of Wurzburg Germany, in November 1895 (Fischbach 2003). Digital Radiography has evolved over the years from using screen film technology to digital imaging; sometimes called Filmless Radiography (Marshal et al 2006). It has become technically possible and economically feasible that digital imaging technology is capable to challenge screen film screen technology for Projection Radiography (Gallet 2009) this has been made possible by technological advancements, such as high luminance and high resolution display monitors combined with high definition computer work station and a decline in the price of computer technology. This shift in technology is gradually finding its way to in to developing countries.

Rejects, deletion, and subsequent retakes of diagnostic X-ray images impose professional and ethical challenges with radiological imaging, it exposes patients to unnecessary ionizing radiation and added inconveniences (Jacobson A 1972) traditional rejects, deletion, retake rates for film based departments have been documented to be in the range of 10 to 15percent (Akhtar W 2008) and their main cause has been attributed to incorrect exposures, due to limited range of screen film systems. A series of research papers have reported rejects, deletion and retake rates in digital radiography at around 5\% (Foos DH 2009, Peer S 2001, Peers 1999, Weather burn GC 1990, Honea R 2002. 
These possess the question whether the reject rates are really as with film system or more and why the problem did not vanish with digital revolution as earlier presumed.

The prevalence of Digital Radiography has been increasing rapidly in the work practice of Radiography. The utilization of digital imaging in education (teaching and learning) has great impact for under graduate as well as continuous education. Moreover, the digital image is effective in that it can be used with high quality and presentation. And in this technique provide beneficial effects on the academic field. In present times, the PACS technologist and radiographers are competent professionals who use this method in the diagnostic techniques for more advanced results in least time. The rapidity of this technique has increased significance and acceptability with the passage of time (Carine JA 2003).

Medical diagnostic X-rays are the largest man-made source of ionizing radiation received by the members of the general public (Nasrollah et al, 2012). The term reject refers to the radiographs of patients that are judged by the technologists acquiring the images to be clinically unacceptable and needing to be repeated. This is one of the commonest problems which practicing technologist and students during internship face as they are allowed to carry out exams under little or no supervision, they turn to exploit digital radiography by judging images, deleting some and doing retakes, forgetting the dose to patient, in which case the patient dose barrier is or are broken irradiating the client unnecessarily, considering the effect of radiation on cells.

This study will help implement solutions to the high image reject rates and retakes, hence reducing patient dose. Also, this study will help improve technologist knowledge on the PACS and its proper use.

The study seeks to answer questions like what is the degree of image rejects deletion and retakes, and what are the courses and finding impacts of Digital Radiography on work practice at CRIMO. The reason why, the main objective of this study was to assess digital radiography practices at CRIMO.

\section{Methods and materials:-}

\section{Study design:-}

This study was a descriptive cross sectional designed.

\section{Study area and justification:-}

The study was carried out at the Bafoussam Regional Hospital because the unit has a CD radiographic system; it is located in the west region of Cameroon.

\section{Spopulation:-}

The study included medical imaging technologists and imaging students on internship at that time.

\section{Inclusion Criteria:-}

The study included technologist working at the Bafoussam Regional Hospital, who have had at least six months and above of working experience.

\section{Exclusion Criteria:-}

The study excluded all practicing students who have had less than six months internship and all non-imaging workers.

\section{Sampling:-}

\section{Sample size calculation:-}

Sample size calculation gave a sample of 384 radiographs to be studied. Given the internship period and the productivity of the hospital, I decided to augment the sample size to 500 radiographs.

\section{Sampling Methods:-}

A random sampling technique was used as this gave equal opportunities to choose radiographs.

\section{data collection procedures:-}

Data was collected differently for various objectives for reject rate analysis, a table was made containing columns and rows were information on rejects was filled by the researcher based on exam encountered giving reasons for 
rejects and the numbers. To assess effects of Digital Radiography on work flow and profession, technologist and practicing students were given questionnaires to fill. Data was collected using, Observation forms, structured questionnaires and Clinical examination (radiographs).

\section{Data management and analysis:-}

15 structured questionnaires were distributed among the participants, all questionnaires were properly filled, Data was coded and typed on excel then was analyzed using statistical package for social sciences (SPSS) version 20.0 for analysis and presented on tables,.

\section{Ethical consideration:-}

The study was carried out paying attention to ethical principles of autonomy, non-maleficence, and beneficence.

\section{Limitations:-}

The internship period was just four weeks; the protocol involved for authorization to collect data also chopped part of the time; language was a barrier since the study was carried out in a French speaking region.

\section{Definition of Terms:-}

\section{Computerized:-}

to control, perform, process, or store (a system, operation, or information by means of an electronic computer or computers (http//www.dictionary.com/ computerized)

\section{Digital Radiography-}

it is a form of $\mathrm{x}$ ray imaging where digital $\mathrm{x}$ ray sensors are used instead of traditional photographic(http//www.dictionary.com/digital radiography)

\section{Scope and Delimitations:-}

The study was carried out at the Bafoussam Regional Hospital and the participants were technologist and practicing students present at the hospital at that time and radiographs taken during that period. The study was limited to assessing retake criteria, retake rate and assess Digital Radiography practice at CRIMO

\section{Results:-}

Occupation in the service:-

Table 1:- Demographic distribution of study population and duration of work experience.

\begin{tabular}{|l|l|l|l|l|l|}
\hline & & Frequency & Percent & Working experience in years & Cumulative Percent \\
\hline Valid & $\begin{array}{l}\text { Practicing } \\
\text { students }\end{array}$ & 10 & 66.7 & $1-4$ & 66.7 \\
\cline { 2 - 7 } & technologist & 5 & 33.3 & $4+$ & 100.0 \\
\cline { 2 - 6 } & Total & 15 & 100.0 & & \\
\hline
\end{tabular}

From the table, practicing student who made up majority $10(66.7 \%)$ of the total population and 5(33.3\%) technologists who made up the minority of the population. it was also found out that majority of the participants had years of working experience ranging from $1-4,13(86.7 \%)$, while the minority had 4 years and above experience $2(13.3 \%)$ 
Reasons for image Retake:-

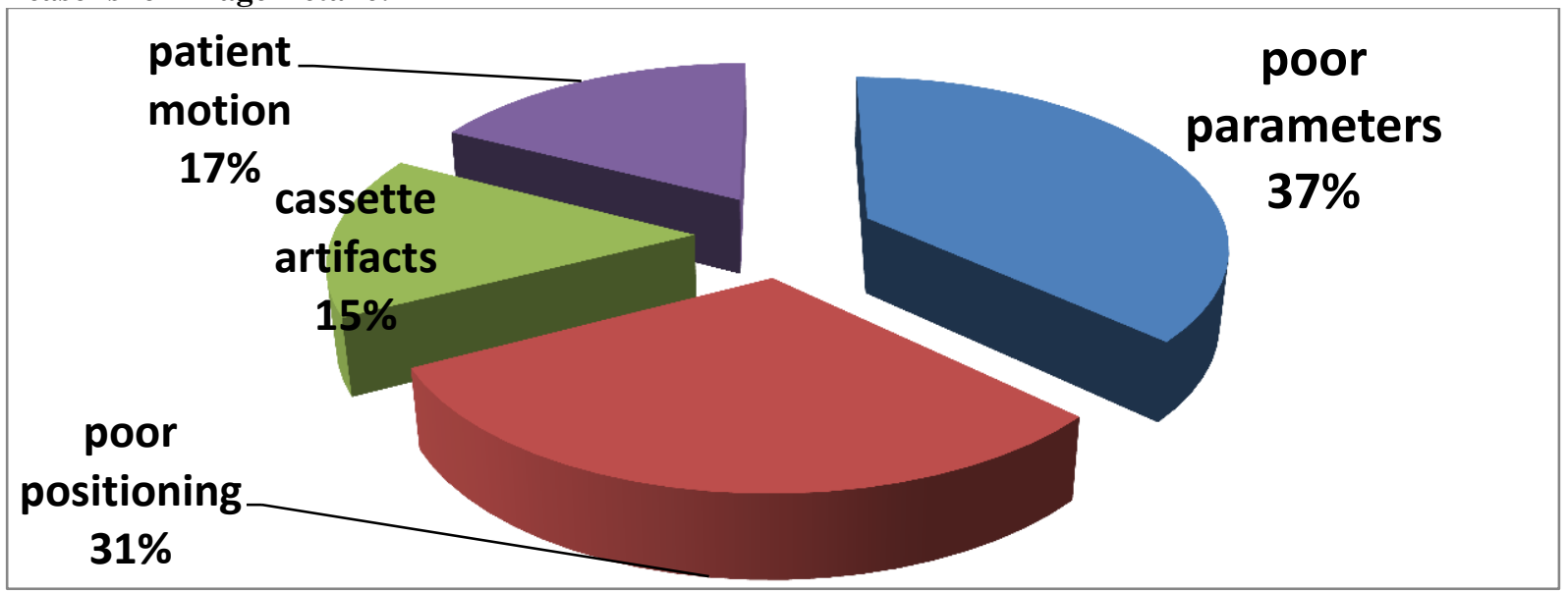

Figure 1:- Proportions of image retakes and reasons

From the figure, most of the retakes (37\%) was due to poor parameters, $31 \%$ due to poor positioning of patient, $17 \%$ due to patient motion and $15 \%$ due to cassette artifacts.

Digital Radiography has improved on performance and work flow:-

Table 2:- participant's opinions on the effect Digital Radiography on work flow and performance

\begin{tabular}{|l|l|l|l|l|l|}
\hline & & Frequency & Percent & Valid Percent & Cumulative Percent \\
\hline Valid & improved & 12 & 80.0 & 80.0 & 80.0 \\
\cline { 2 - 6 } & reduced & 3 & 20.0 & 20.0 & 100.0 \\
\cline { 2 - 6 } & Total & 15 & 100.0 & 100.0 & \\
\hline
\end{tabular}

From the table, it was discovered that most of the participant $12(80 \%)$ think DR has improved work flow and performance while only $3(20 \%)$ of the respondents had the opinion it has reduced work flow and performance.

Table 3:- the effect of Digital Radiography on participants, and knowledge on the PACS

\begin{tabular}{|l|l|l|l|l|}
\hline & & Frequency & Percent & Cumulative Percent \\
\hline Valid & Parameters & $\mathbf{9}$ & $\mathbf{5 0 . 0}$ & $\mathbf{5 0 . 0}$ \\
\cline { 2 - 5 } & Collimation & $\mathbf{9}$ & $\mathbf{5 0 . 0}$ & $\mathbf{5 0 . 0}$ \\
& Know PACS & $\mathbf{7}$ & $\mathbf{4 6 . 7}$ & $\mathbf{4 6 . 7}$ \\
& Don't know PACS & $\mathbf{8}$ & $\mathbf{5 3 . 3}$ & $\mathbf{5 3 . 3}$ \\
\hline
\end{tabular}

From the table it was discovered that $9(50.0 \%)$ of the participants opinion had difficulties with collimation and 9(50.0\%) difficulties with parameters. From the table, it was discovered that most of the respondents $8(53.3 \%)$ did not know of the PACS while a lesser number 7(46.7\%) knew.

Source of information on the PACS:-

Table 4:- source of information on the PACS

\begin{tabular}{|l|l|l|l|l|l|}
\hline & & Frequency & Percent & Valid Percent & Cumulative Percent \\
\hline Valid & School & 2 & 28.6 & 28.6 & 28.6 \\
\cline { 2 - 6 } & Internet & 5 & 71.4 & 71.4 & 100.0 \\
\cline { 2 - 6 } & Total & 7 & 100.0 & 100.0 & \\
\hline
\end{tabular}

From the table, it was noticed that most of the respondents $5(71.4 \%)$ had their information from the internet while only $2(28.6 \%)$ had their information from school 


\section{Problem identified:-}

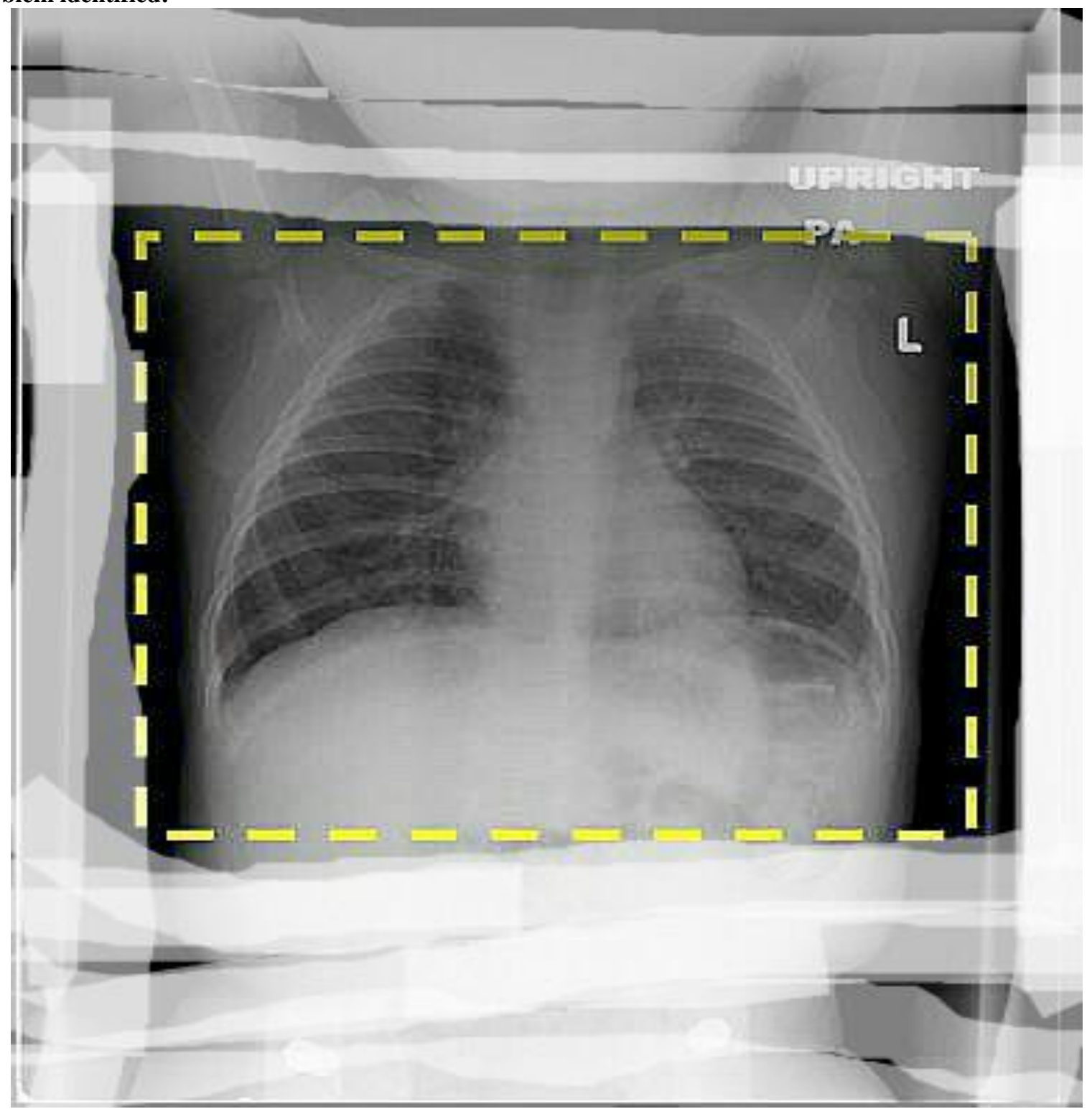

Figure 2: problem identified.

From the figure, patient body parts out of the field of interest seen resulting from bad collimator, and the presence of cassette artifacts

\section{Discussions:-}

The results on figure 1, show the deletion rate which is very high compared to standards and international studies on Digital Radiography. In this study, 500 images were sampled at random, out of which 230 retakes were made, of this 230 retakes, $37 \%$ were as a result of poor parameters, $31 \%$ resulting from poor patient positioning, $17 \%$ for patient motion and 15\% resulting from cassette artifacts, which is exceptionally high and falsifies the standard by the American radiology society at a retake rate of 1 to $3 \%$. DR equipment comes with a control panel with default parameters for imaging various structures or organs, radiographers take advantage of this and end up losing the skill of the art which involves keying in parameters based on the size of the patient or organ in question to be imaged. positioning was the preceding reason for retakes, it was due to the fact that technologist took advantage of post processing, as images can be reshaped after imaging, prior to printing, so collimation and centering was poorly done as wide as they wished exposing the patients unnecessarily. Moreover the next factor was patient motion which 
rated $37 \%$ of total retakes the main reason for this was due to poor radiography practice as the patients involved were not given clear instructions on the exam procedure. Still in this line retake due to patient motion was followed by cassette artifacts it resulted in $15 \%$ of total image retakes, this reason accounted for this much value because irregular quality control check programs, and the lack of a quality control committee for the service at the time of the study. It was also realized that there is no criteria for image retake. Never the less image retake can be can be greatly minimized to the standard through the implementation of the ALARA principle and patient dose greatly reduced.

From the results, majority of participated radiographers $(80 \%)$ thought the transition from screen film to Digital Radiography or filmless radiography has not only improved on work flow greatly but has also increased on the performance of the service, Despite the increased productivity and efficiency of the service, some negative effects on the radiology profession were recorded as shown on table 2, where $60 \%$ of participants agreed that Digital Radiography has direct effect on their professional skills which was either parameter related problems or collimation related problems or both. In this study, there was no picture archiving and communication system (PACS) installed in the institution at the time of the study. The main reason being the fact that DR is still new and is still gaining its place in the developing region. It was also discovered that there is a gap in the number of technologist with knowledge on the PACS as illustrated on table 3, by a ratio of $46.7 \%$ of participants who had knowledge on PACS to 53.3\% who had no knowledge on the PACS. The reason for the greater majority $53.3 \%$ was mainly because DR was not thought in the various institutions, and the participants had not read much on DR from the media or other sources. Of the $46.7 \%$ who had knowledge on the PACS, only a few of them $(28.6 \%)$ had the information from school and $71.4 \%$ from the internet. Never the less, of the $28.6 \%$ who had the knowledge from school, most of them said lecturers only mentioned them during discussions and it was not treated as a topic on its own. This is evidence that institutions training imaging personnel do not update the curriculum as the field advances, it then becomes challenging for radiographers who will find themselves in institutions with the PACS installed due to employment or transfer, it becomes imperative for DR and PACS to be added to the curriculum of medical imaging institutions and student encouraged to read more on advanced technology in medical imaging.

Figure 2, shows the three main problems that were identified with the digital system in use at the time of the study, the problems were: bad collimator, low storage space for images and no quality control checks. During this study, it was discovered that of the 500 sampled radiographs, 373radiographs showed structures out of the collimation field as shown on figure 2 and the other images which did not show any images out of the area of interest was due to low exposures used on organ in question due to its thickness or density. The second problem was that of cassette artifacts, out of the 500 sampled images, 35 had problems resulting from various forms of cassette artifacts. The main reason for this at the study hospital was due to lack of adequate quality control as prescribed by the machine manufacturer or American radiology society and the bureau for radiological health New Jersey as also done by Donald Peck 2015.

The last problem was that of image storage and retrieval, the hard disc used at the time for storage was only 180 GB, and so old images were automatically deleted after a certain maximum number of images were attained, so images cannot be retrieved after a few months.

\section{Conclusion:-}

The results and discussion have made feasible the detected deficiency in the department like no criteria for image reject and of deletion, positioning skills, radiographic parameters and no quality control, the study has also shown that DR has improved on work flow and performance and has directly affected negatively the radiographers skills, the results have also shown that most radiographers have little or no knowledge on the PACS, it was also discovered that the digital radiographic system has at least three problems, in that light it was the concluded that Digital Radiography is poorly practiced at the Bafoussam regional hospital based on the objectives of the study.

\section{Recommendations:-}

In line with the above results, it is recommended that quality control programs should be made and implemented for the service. 


\section{References:-}

1. Akesson L, Håkansson J, Rohlin M, Zöger B. An evaluation of image quality for the assessment of the marginal bone level in panoramic radiography. A comparison of radiographs from different dental clinics. Swed Dent J 1993; P17: 9-21.

2. Australian Council of Healthcare Standards (2000).

3. Berkhout WER, DA Beuger, GCH Sanderink and PF van der Stelt The dynamic range of digital radiographic systems: dose reduction or risk of overexposure? Dentomaxillofacial Radiology (2004) 33, 1-5.

4. Bjørn Hofmann1, Tine Blomberg Rosanowsky2, Camilla Jensen2 and Kenneth Hong Ching Wah2 Image rejects in general direct digital radiography

5. Compliance Guidance for RADIOGRAPHIC QUALITY CONTROL New Jersey Department of Environmental Protection Bureau of Radiological Health http://www.state.nj.us/dep/rpp

6. Hofmann B, Waaler D. Retake of radiological images: the problem that could not be digitally abolished [in Norwegian]. Hold Pusten 2008;7: P12-15.

7. Hofmann B. Too much of a good thing is wonderful? A conceptual analysis of excessive examinations and diagnostic futility in diagnostic radiology. Med Health Care Philos 2010;13: P139-148.

8. http//www.dictionary.com/ computerized

9. International Commission on Radiological Protection. Managing patient dose in digital radiology. ICRP Publication 93. Ann ICRP. (2004). 34(1), p1-73

10. Miles DA, Van Dis ML, Williamson GF, Jensen CW: Radiographic Imaging for the Dental Team. 4th Ed. St. Louis, Saunders, 2009: P139-52

11. Mohamed M Abuzaid, Rasha Saad, W. Elshami, S. Alyafei The Effect Of Digital Imaging On Radiography Work Practice international journal of scientific \& technology research volume 4, issue 07, july 2015

12. Nakano, Y, Togashi, K., Nishimura, K., Itoh, K., Fujisawa, I., Asato, R., Adachi, H., Itoh, H, and Torizuka, K.: Stomach and duodenum: Radiographic magnification using computed radiography (CR). (1986). Radiology, $160, \mathrm{P} 383-387$

13. Nasrollah Jabbari, Ahad Zeinali1, Leili Rahmatnezhad. Patient dose from radiographic rejects/repeats in radiology centers of Urmia University of Medical Sciences, Iran ( 2011) p 1

14. Prieto C, Vano E., J. I. Ten, J. M. Fernandez, A. Iñiguez, N. Arevalo, A. Litcheva, E. Crespo, Floriano, and D. Martinez Image Retake Analysis in Digital Radiography Using DICOM Header Information 2 From the Radiology Department, Medicine School, Complutens University, 28040, Madrid, Spain. 